\title{
PENGARUH UTSAWA DHARMA GITA PADA PESERTA DI DAERAH ISTIMEWA YOGYAKARTA TAHUN 2017
}

\author{
I Nyoman Santiawan \\ Dosen Sekolah Tinggi Hindu Dharma \\ Klaten Jawa Tengah
}

\begin{abstract}
Abstrak
Utsawa Dharma Gita tingkat nasional merupakan ajang kompetisi bagi lembaga Hindu yang ada di Indonesia. Dalam penyelenggaraan kegiatan Utsawa Dharma Gita banyak persiapan yang harus dilakukan. Bagi setiap daerah, tantangan yang paling menjadi kendala setiap tahunya untuk diluar daerah bali adalah melengkapi formasi peserta lomba. Disamping itu, kendala lainya adalah kurangnya pendampingan peserta pada saat melakukan latihan beberapa penyebab, masih kurangnya minat generasi untuk mengikuti kegiatan lomba. Dari hasil penelitian yang didapat, di luar daerah Bali perlu diadakannya kerja sama yang mendalam antara lembaga Hindu dan Guru Agama Hindu. Dengan peran Guru Agama Hindu inilah menjadi jalan keluar dalam kendala kesulitan dalam melengkapi formasi peserta. Melalui pendekatan yang dilakukan guru, dapat menarik minat siswa untuk mengikuti perlombaan. Hasil penelitian membuktikan pendampingan yang rutin menjadikan peserta lebih percaya diri dan dapat menyelesaikan setiap kendala yang dihadapi peserta. Penelitian ini memeberikan idnikato, siswa atau generasi yang ikut lomba utsawa dhrama gita mengalami perubahan yang cukup signifikan. Yaitu peserta menjadi meningkat sradda dan bhakti, mengenal dan mencintai kebudayaan serta mendapat nilai-nilai pendidikan, seperti nilai pendidikan religi, nilai pendidikan budaya dan nilai pendidikan sosial. Dengan mengikuti lomba, kemandirian dan kebahagiaan generasi Hindu dapat tercipta dan memberikan pengalaman yang sangat berharga bagi generasi muda Hindu.
\end{abstract}

Kata Kunci: Utsawa Dharma Gita, Lomba, Nilai dan Hasil 


\section{PENDAHULUAN}

Pengaruh perkembangan zaman dan pola hidup sangat komplek dan cepat mengalami perubahan dalam kehidupan berbangsa dan bernegara. Dengan perkembangan berbagai macam bidang, pola berpikir dan berprilaku manusia juga mengalami perubahan. Tidak hanya di kehidupan bidang ekonomi, politik, sosial, budaya tetapi juga bidang agama juga mengalami perubahan. Dewasa ini banyak kasus-kasus kehidupan beragama yang menjadi perhatian yang sangat dalam. Salah satunya adalah kurang memahami ajaran agama yang sebenarnya, sehingga muncul tindakan atau sikap yang dapat menyinggung kelompok lain. Untuk mengurangi kejadian atau gesekan-gesekan antara pemeluk agama, pemerintah bekerja keras melakukan perbaikan dan peningkatan pola pembinaan kehidupan beragama masyarakat. Mulai dari pengangkatan penyuluh Non PNS sampai memberikan alokasi lebih untuk memprogramkan kegiatan yang bersifat membangun nasionalisme dan meningkatkan keyakinan serta bhakti terhadap agama. Program-program kerja terus ditambah, baik program baru maupun program yang lama.

Dirjen Bimas Hindu yang menjadi tangan kanan pemerintah dalam melakukan pembinaan kehidupan beragama, melakukan terobosan-terobosan baru dalam membina umat dan meningkatkan program unggulan yang sudah menjadi agenda tetap menjadi kegiatan yang strategis untuk mencapai apa yang menjadi tujuan pemerintah. Salah satu program/agenda tetap Dirjen Bimas Hindu adalah Utsawa Dharma Gita. Dengan kegiatan Utsawa Dharma Gita, diharapkan mampu meningkatkan Sradha dan Bhakti umat, terutama Peserta yang terlibat dalam kegiatan tersebut. Namun perlu disadari, bahwa Utsawa Dharma Gita bukanlah menjadi tujuan utama agama Hindu maupun manusia (umat) Hindu. Utsawa Dharma Gita hanyalah sebagai sarana sosialisasi kepada umat Hindu maupun non Hindu, bahwa di dalam agama Hindu terdapat Dharma Gita yang setiap saat dapat dilantunkan sebagai tanda bhakti kepada Ida Sang Hyang Widhi Wasa. Di dalam Bhagavata Purana (VII.5.23) disebutkan ada 9 bentuk bhakti kepada Ida Sang Hyang Widhi Wasa, satu di antaranya adalah Kirtanam, yakni mengucapkan atau menyanyikan sloka-sloka suci atau nama-nama Tuhan YME (Pandejuliana, 2012).

Pelaksanaan kegiatan Utsawa Dharma Gita, tujuan utamannya adalah bagaimana umat menjadi lebih paham, meyakinin dan patuh terhadap ajaran-ajaran agama. sehingga dalam membawakan masing-masing katagori hendaknya dapat menjiwai dan memahami prosesnya. Sangat disayangkan jika kegiatan Utsawa Dharma Gita dipandang hanya sebagai suatu perlombaan dan mendapatkan juara. Tidak sedikit saat ini yang menganggap bahwa kegiatan Utsawa Dharma Gita sebagai ajang perlombaan dan motivasi menjadi juara. Kegiatan tingkat nasional yang menghabiskan biaya yang cukup banyak ini, menjadi moment yang sangat penting sehingga harus digunakan dengan baik kesempatan ini sebagai peningkatan sradha dan bhakti serta rasa nasionalisme pada setiap umat. Kehidupan keagamaan yang harmonis merupakan salah satu pilar keragaman yang harus senantiasa dijaga dan dikembangkan. Kegiatan keagamaan Utsawa Dharma Gita atau seni baca Weda bagi agama Hindu tidak hanya menjadi pengisi pembangunan kemasyarakatan namun lebih jauh menjadi perekat keberagaman sekaligus sebagai filter pengaruh-pengaruh buruk yang dapat merusak tatanan kehidupan dalam bermasyarakat.

Problemanya adalah, bahwa secara emperikal Dharma Gita yang diUtsawakan selama ini hanya dimonopoli oleh nyanian-nyanyian dharma yang sudah membudaya yang berasal hanya dari satu suku bangsa penganut/pemeluk agama Hindu saja, yakni suku bangsa Bali. Problema demikian itu tentu dinilai tidak kondusif dan berimplikasi negatif terhdap eksistensi agama dan umat Hindu di Indonesia. Maka solusi yang dapat diberikan terhadap problema tadi adalah, bahwa dalam setiap penyelenggaraan UDG, secara imperatif harus 
mengakomodasi, dan mengapresiasi serta merefleksikan budaya-budaya dari suku-suku bangsa serta sampradaya-sampradaya yang ada di Indonesia yang ajaran-ajarannya berlandaskan agama Hindu (Pandejuliana, 2012)

Kesulitan dalam mencari Peserta masih ditemukan, selain minimnya umat yang berada di luar daerah Bali, juga yang menjadi penyebab adalah kurang percaya dirinya sumberdaya manusia, sehingga banyak kategori lomba yang kosong. Permasalahan ini harus segera ditangani, sehingga dikemudian hari tidak ada katagori lomba yang tidak ada Pesertanya untuk setiap daerah. Penulis melakukan penelitian yang akan mengugkapkan sisi lain yang akan didapat para Peserta lomba dalam mengikuti kegiatan pelaksanaan Utsawa Dharma Gita. Dengan banyaknya manfaat yang akan diterima, dan menginformasikan kepada seluruh lapisan masyarakat sehingga akan menjadi suatu ajang yang dinanti-nanti dan menjadi rebutan untuk diikuti.

Untuk mendapatkan hasil yang akurat dan untuk memudahkan penulis dalam melakukan penelitian ini, maka penulis menggunakan metode penilitian. Penelitian yang digunakan dalam penelitian ini adalah penelitian kualitatif deskriptif, mengingat permasalahan yang ingin diangkat merupakan masalah sosial keagamaan. Tempat penelitian di Daerah Istimewa Yogyakarta, dengan cara observasi, pengamatan, dokumentasi dan wawancara, yang merupakan sumber data yang utama, sedangkan cara analisis datanya yaitu dengan mengamati, memahami, dan menafsirkan setiap fakta atau data yang telah dikumpulkan serta hubungan di antara fakta-fakta atau variable merupakan terkait dalam hipotesis (Sugiyono, 2005 : 244). Data penelitian yang peneliti peroleh melalui observasi dan wawancara dengan informan selama penelitian di lapangan selanjutnya dipaparkan, kemudian dicari pokokpokok penting yang terkandung di dalamnya sehingga dapat di ketahui dengan jelas maknanya. Data yang peneliti peroleh selanjutnya diseleksi dan di kode untuk memperoleh konsep yang lebih sederhana sehingga relatif lebih mudah dipahami.

\section{PEMBAHASAN}

\section{Gambaran Umum Utsawa Dharma Gita}

Berdasarkan kitab suci Weda, Utsawa Dharma Gita pada hakekatnya adalah Phalasruti, Phalasloka dan Phalawakya. Phalasruti mengandung makna pahala dari pembacaan kitabkitab sruti atau wahyu yang pada umumnya disebut mantra yang berasal dari Hyang Widhi. Phalasloka adalah pahala dari pembacaan kitab-kitab susastra Hindu seperti kitab Itihasa, yakni Ramayana dan Mahabarata. Phalawakya adalah tradisi pembacaan karya sastra Jawa Kuna, berbentuk prosa atau parwa. Utsawa berarti festival atau lomba, sedangkan Dharma Gita adalah nyanyian suci keagamaan. Dengan demikian, Utsawa Dharma Gita adalah festival atau lomba nyanyian suci keagamaan Hindu. Utsawa Dharma Gita sebagai kidung suci keagamaan Hindu telah lama berkembang di masyarakat melalui berbagai pesantian, baik yang ada di Bali maupun luar Bali. Sebelum menasional, Utsawa Dharma Gita dilaksanakan Pemda Bali dalam bentuk lomba kekawin dan kidung. Penggunaan Dharma Gita dalam berbagai bentuk kegiatan keagamaan sangat membantu menciptakan suasana hening, hikmat/kusuk yang dipancari getaran kesucian dengan jenis yadnya yang dilaksanakan (Pandejuliana, 2012).

Ada pun tujuan dari penyelenggaraan Utsawa Dharma Gita Tingkat Nasional ini adalah ada dua yaitu tujuan umum dan tujuan khusus.

a) Tujuan Umum 
1. Meningkatkan pengetahuan, pemahaman, penghayatan dan pengamalan kitab suci Weda;

2. Meningkatkan sraddha dan bhakti sebagai landasan terbentuknya susila Hindu;

3. Melestarikan dan mengembangkan Dharma Gita;

4. Memantapkan kerukunan intern umat Hindu yang dinamis dan faktual;

5. Menyamakan persepsi tentang Dharma Gita;

6. Meningkatkan kajian terhadap kitab suci Weda.

b) Tujuan Khusus

1. Meningkatkan keterampilan membaca kitab suci Weda/kidung-kidung keagamaan;

2. Meningkatkan penguasaan materi ajaran agama Hindu;

3. Memperluas wawasan tentang kidung keagamaan daerah;

4. Merintis kader-kader pendharmawacana;

5. Memilih Peserta terbaik Utsawa Dharma Gita Tingkat Nasional;

6. Menemukan solusi terbaik berbagai permasalahan tentang penyelenggaraan Utsawa Dharma Gita.

Utsawa Dharma Gita Tingkat Nasional telah berlangsung sebelas (12) kali berturutturut. Panitia pelaksana Utsawa Dharma Gita Tingkat Nasional ini dibentuk dan ditetapkan dengan Surat Keputusan Menteri Agama RI. Adapun pelaksanaan Utsawa Dharma Gita tingkat nasional pertama sampai ke sebelas antara lain:

a) Utsawa Dharma Gita pertama dilaksanakan di Denpasar-Bali, pada tahun 1978. Saat itu namanya Pembinaan Seni Sakral. Jenis kegiatannya antara lain : pembinaan nyanyian pengiring tari Sanghyang, jenis-jenis kidung dan kekawin dengan kekhasan daerah masing-masing, yang diikuti utusan se-provinsi Bali.

b) Utsawa Dharma Gita II berlangsung di Denpasar pada tahun 1979. Jenis kegiatannya antara lain : parade seni, pameran foto, kekawin, kidung macepat dan phalawakya, yang diikuti oleh utusan kabupaten se-provinsi Bali.

c) Utsawa Dharma Gita III juga berlangsung di Denpasar pada tahun 1980. Jenis kegiatan Utsawa yang dilaksanakan : parade seni, pameran foto, kekawin, kidung, dan phalawakya, yang diikuti utusan kabupaten se-provinsi Bali dan Lombok.

d) Utsawa Dharma Gita Tingkat Nasional IV, berlangsung di Taman Mini Indonesia Indah (TMII) Jakarta, pada tahun 1991. Jenis kegiatannya : parade seni, Utsawa pembacaan Sloka, Utsawa pembacaan Phalawakya, Dharma Widya, parade kidung daerah, sarasehan dan pameran. Juara umum diraih Peserta provinsi Bali.

e) Utsawa Dharma Gita Tingkat Nasional V, dilaksanakan di Solo, Surakarta, Jawa Tengah pada tahun 1993. Jenis kegiatan : parade seni, Utsawa pembacaan Sloka, Utsawa pembacaan Phalawakya, Dharma Widya, parade kidung daerah, sarasehan dan pameran. Juara umum diraih Provinsi Jawa Tengah.

f) Utsawa Dharma Gita Tingkat Nasional VI dilaksanakan di Palangkaraya, Kalimantan Tengah pada tahun 1996. Jenis kegiatan : parade seni, Utsawa pembacaan Sloka, Utsawa pembacaan Phalawakya, Dharma Widya, parade kidung daerah, sarasehan dan pameran. Juara umum diraih Provinsi Bali. 
g) Utsawa Dharma Gita Tingkat Nasional VII, dilaksanakan di Taman Mini Indonesia Indah (TMII) Jakarta pada tahun 2000. Jenis kegiatan : parade seni, Utsawa pembacaan Sloka, Utsawa pembacaan Phalawakya, Dharma Widya, parade kidung daerah, sarasehan dan pameran. Juara umum diraih Provinsi Bali.

h) Utsawa Dharma Gita Tingkat Nasional VIII, dilaksanakan di Mataram, Nusa Tenggara Barat pada tahun 2002. Jenis kegiatan : parade seni, Utsawa pembacaan Sloka, Utsawa pembacaan Phalawakya, Dharma Widya, parade kidung daerah, sarasehan dan pameran. Juara umum kembali diraih Provinsi Bali.

i) Utsawa Dharma Gita Tingkat Nasional IX, dilaksanakan di Bandar Lampung pada tanggal 13 s/d 19 Juli 2005. Tema UDG Tingkat Nasional IX Tahun 2005 adalah : "Melalui Utsawa Dharma Gita Nasional IX Kita Tingkatkan Kesadaran Humanisme Hindu dalam Rangka Persatuan dan Perdamaian”. Jenis kegiatan : parade seni, Utsawa pembacaan Sloka pasangan Remaja putra-putri, Utsawa pembacaan Phalawakya pasangan remaja dan dewasa putra-putri, Dharma Widya tingkat Sekolah Dasar (SD), Sekolah Menengah Pertama (SMP), Sekolah Menengah Atas (SMA), Dharma Wacana tingkat remaja dan dewasa, Utsawa kidung/lagu-lagu keagamaan daerah, sarasehan dan pameran. Utsawa Dharma Gita Tingkat Nasional IX diikuti Peserta dari 29 provinsi dan utusan negara sahabat seperti India. Juara umum diraih oleh Provinsi Nusa Tenggara Barat.

j) Utsawa Dharma Gita Tingkat Nasional X, dilaksanakan di Arena Taman Persatuan Sulawesi Tenggara, di Kota Kendari, Sulawesi Tenggara pada tanggal 4 s/d 7 Agustus 2008. Tema yang diusung dalam Utsawa Dharma Gita kali ini adalah: "Melalui Utsawa Dharma Gita Tingkat Nasional $X$ Kita Tingkatkan Kesadaran Multikulturalisme Guna Mewujudkan Kebersamaan, Pengabdian dan Integritas Bangsa”. UDG Nasional X Tahun 2008 diikuti oleh Peserta sebanyak 1.321 orang yang berasal dari 32 provinsi. Jenis kegiatan: Pawai atau Gita Pradaksina, Utsawa atau lomba (lomba pembacaan Phalawakya, lomba pembacaan Sloka, Dharma Widya (Cerdas Cermat), lomba Dharma Wacana, lomba Menghafal Sloka, dan lomba Kidung Daerah), pameran, lomba daerah (stand pameran terindah, lomba penjor, lomba ogoh-ogoh dan lomba baleganjur), Sarasehan dan Pesamuhan Agung Parisada. Juara umum diraih oleh provinsi Bali.

k) Utsawa Dharma Gita Tingkat Nasional XI, dilaksanakan di Art Centre Denpasar Bali pada tanggal 10 s/d 14 Juni 2011. Tema Utsawa Dharma Gita Tingkat Nasional XI tahun 2011 adalah : "Melalui Utsawa Dharma Gita Tingkat Nasional XI Kita Mantapkan Pemahaman, Penghayatan dan Pengamalan Ajaran Suci Weda serta Memperluas Wawasan Keagamaan Umat Hindu Indonesia”. Utsawa Dharrma Gita Tingkat Nasional XI dibuka oleh Bapak Presiden RI. Jenis kegiatan yang dilaksanakan, yaitu: Pawai Budaya Hindu, Utsawa atau lomba (Utsawa pembacaan Phalawakya, Utsawa pembacaan Mantra/Sloka, Utsawa Dharma Wacana, Utsawa Dharma Widya (cerdas cermat), Utsawa Menghafal Mantra/Sloka terbanyak, dan Utsawa Kidung Keagamaan Daerah), Pameran Budaya dan Keagamaan Hindu, Pentas Seni Bernafaskan Hindu, Sarasehan dan Tirtha Yatra. UDG Nasional XI kali ini diikuti oleh seluruh provinsi di Indonesia (33 provinsi) dengan jumlah Peserta 1.320 orang. Juara umum diraih oleh provinsi Bali. 
1) Utsawa Dharma Gita Tingkat Nasional XII Tahun 2014 dilaksanakan di Hotel Mercure Ancol Jakarta 11 s/d 14 Juli 2014 dengan mengambil tema "Melalui Utsawa Dharma Gita Tingkat Nasional XII Kitamantapkan Pemahaman, Penghayatan Dan Pengamalan Ajaran SuciWeda Dalam Rangka Memperkokoh Persatuan Dan Kesatuan Bangsa". Utsawa Dharma Gita dibuka oleh Menteri Agama Lukman Hakim Saifudin di dampingi oleh Sekjen Menag Nur Syam. Jenis kegiatan yang dilaksanakan, yaitu: Pawai Budaya Hindu, Utsawa atau lomba (Utsawa pembacaan Phalawakya, Utsawa pembacaan Mantra/Sloka, Utsawa Dharma Wacana, Utsawa Dharma Widya (cerdas cermat), Utsawa Menghafal Mantra/Sloka terbanyak, dan Utsawa Kidung Keagamaan Daerah), Pameran Budaya dan Keagamaan Hindu, Pentas Seni Bernafaskan Hindu, Sarasehan dan Tirtha Yatra. UDG Nasional XII diikuti oleh seluruh provinsi di Indonesia (33 provinsi) dengan jumlah Peserta 2.700 orang. Juara umum diraih oleh provinsi Bali.

m) Utsawa Dharma Gita Tingkat Nasional XIII Tahun 2017 dilaksanakan di Palembang Sumatera Selatan pada tanggal 06 s/d 10 Juli 2017 dengan mengambil tema "Utsawa Dharma Gita Tingkat NasionalXIII 2017: Wahana Penguatan Pemahaman, Penghayatan dan Pengamalan Ajaran Agama Hindu Sebagai Wujud Revolusi Mental". Utsawa Dharma Gita dibuka oleh Menteri Agama Lukman Hakim Saifudin. Jenis kegiatan yang dilaksanakan, yaitu: Pawai Budaya Hindu, Utsawa atau lomba (Utsawa pembacaan Phalawakya, Utsawa pembacaan Mantra/Sloka, Utsawa Dharma Wacana, Utsawa Dharma Widya (cerdas cermat), Utsawa Menghafal Mantra/Sloka terbanyak, dan Utsawa Kidung Keagamaan Daerah), Pameran Budaya dan Keagamaan Hindu, Pentas Seni Bernafaskan Hindu, Sarasehan dan Tirtha Yatra. UDG Nasional XII diikuti oleh seluruh provinsi di Indonesia (33 provinsi) dengan jumlah Peserta 1.511 orang. Juara umum diraih oleh provinsi Bali.

\section{Persiapan yang disiapkan oleh para peserta lomba dalam pelaksanaan Utsawa Dharma Gita}

Mengikuti Utsawa Dharma Gita tingkat nasional merupakan suatu kesempatan bagi para Peserta, karena disamping tampil perserta juga terdorong untuk belajar seni keagamaan Hindu. Dharma Gita, merupakan nyanyian kebenaran yang bawakan dengan penuh penghayatan sehingga dapat meresap kedalam pribadi manusia. Bagi mereka yang tekun mengucapkan mantram-mantram Veda akan mendapat perlindungan dari mantram-mantram Veda itu sendiri (Titib, 1999). Oleh karena itu, para Peserta wajib serius dan benar-benar serta menghayati dalam membaca sloka/mantram. Seperti yang tercantum dalam kitab Nirukta menyatakan:

Seorang yang mengucapkan mantram (Veda) dan tidak memahami makna yang terkandung dalam mantram (Veda) itu, tidak pernah memperoleh penerangan. Seperti halnya sebatang kayu bakar, walaupun disiram denan minyak tanah tidak akan terbakar bila tidak disulut dengan api. Demikian orang yang hanya mengucapkan (membaca) mantram (Veda) tidak mendapatkan cahaya pengetahuan yang sejati, Nirukta I.18.

Dalam persiapan pelaksanaan Utsawa Dharma Gita Tingkat Nasional XII, di Propinsi Yogyakarta melakukan pesiapan dan kesiapan yang dilakukan oleh para pembina, juri maupun Peserta. Latihan yang sering menunjukan keseriusan Peserta D.I Yogyakarta untuk benar-benar menghayati berbagai macam katagori lomba. Selain latihan yang sering, berdasarkan pengamaatan dan wawancara yang telah dilakukan ada beberapa hal penting yang perlu disiapkan oleh Peserta lomba antara lain: 


\section{a) Mental}

Mental menjadi faktor penunjang yang utama dalam kegiatan Utsawa Dharma Gita ini, bagaimana Peserta lomba mengendalikan pikirannya, sehingga pada saat tampil tetap tenang dan siap menang maupun kalah. Bagi yang sering tampil di muka umum berpendapat bahwa kesiapan mental merupakan suatu hal yang tidak utama, lain halnya dengan perserta yang belum terbiasa atau merupakan yang pertamakalinya bagi mereka mengagap persiapan mental adalah yang paling utama. Di setiap pertemuan, tidak jarang para pelatih menekankan bahwa perserta dihimbau lakukan semuanya dengan senang hati dan penuh kecintaan supaya tidak menjadi beban pikiran bagi para Peserta agar dapat mencapai apa yang menjadi tujuan. (Sura, 2001) Oleh karena demikian sifat pikiran itu maka dalam agama ada ajaran untuk mengendalikan agar orang dengan pikiran itu dapat menuju harapan hidup yang dicitacitakan. Memang pikiran manusia tak suka diam, selalu gelisah berbuat, selalu mempunyai keiinginan maju seperti yang tercantum dalam sloka Sarasamuccaya 81.

" Keadaan pikiran itu demikianlah tidak berketentuan jalannya, banyak yang dicitacitakan, terkadang penuh kesangsian, demikianlah kenyataannya. Jika ada orang mengendalikan pikirannya pasti orang itu mendapat kebahagiaan baik sekarang maupun di dunia yang lain"

Peserta Propinsi Yogyakarta merupakan Peserta yang baru dan belum mempunyai pengalaman tampil yang banyak, sehingga berdasarkan hasil wawancara, banyak yang menjawab mental menjadi ssuatu yang utama yang harus disiapkan. Seperti Peserta lomba yang katagori anak-anak. Peserta lomba yang demikian, dibayangi rasa takut akan tampil dihadapan orang banyak dan orang yang belum mereka kenal.

\section{b) Kesehatan}

Kesehatan merupakan menjadi faktor yang penting juga, semua Peserta berpendapat bahwa kesehatan tubuh menjadi kunci bagi para Peserta. Walaupun kesehatan memang sebagian besar dipngaruhi oleh pikiran. Tubuh yang sehat dalam Brahma Purana disebutkan pentingnya tubuh bagi manusia bahwa tubuh merupakan alat untuk mendapatkan Dharma, Artha, Kama dan Moksa (Pudja, 2002).

"Dharmartha kama moksanan sariaram sadhanam"

Sloka di atas mengisyaratkan bahwa tubuh itu adalah alat yang sangat berguna untuk mencapai kebajikan, kebenaran (dharma), kekayaan (artha), kekuasaan, jabatan, pangkat, keinginan (kama), kesenangan dan pembebasan diri dari samsara (moksa). Semua itu bisa didapatkan karena bantuan tubuh, karena itu kecenderungan orang untuk memelihara tubuhnya agar tetap berfungsi optimal adalah sah dan wajar.

Kesehatan penting bagi para Peserta, itulah yang disampaikan oleh Peserta Propinsi Yogyakarta, sehingga hampir semua Peserta lomba menerangkan untuk menjaga kesehatannya, perserta secara teratur melakukan olahraga, menerapkan pola makan yang sehat dan istrirahat yang cukup. Semua itu dilakukan supaya Peserta dapat mengikuti semua kegiatan latihan sampai kegiatan puncak acara sampai dengan selesai.

\section{c) Latihan}

Menurut Sukadiyanto (2005:1) menerangkan bahwa pada prinsipnya latihan merupakan suatu proses perubahan ke arah yang lebih baik, yaitu untuk meningkatkan kualitas fisik kemampuan fungsional peralatan tubuh dan kualitas psikis anak latih. Namun selain latihan fisik, latihan untuk meningkatkan keterampilan juga diperlukan. Keterampilan yang dimiliki Peserta setiap saat diasah dan difokuskan pada kategori lomba yang diambil. Sehingga Peserta lebih menguasai trik dan metode dalam kegiatan Utsawa Dharma Gita. 
Peserta Propinsi Yogyakarta melakukan latihan yang kontinue, mulai dari latihan keterampilan bidang lomba sampai dengan keterapilan penampilan. Berdasarkan wawancara yang telah dilakukan data menunjukan waktu latihan yang cukup sangat membantu Peserta dalam mengasah keterampilan dan tidak sedikit pula yang mengatakan Peserta juga latihan di rumah secara otodidak mengingat latihan yang didampingi pelatih hanya dijadualkan 1 kali dalam seminggu.

\section{d) Materi/Naskah}

Persiapan meteri merupakan suatu yang wajib sebenarnya, namun ada beberapa lomba yang butuh menyiapkan materi dengan mandiri, sebagai contoh lomba Utsawa Dharma Widya dan Lagu/Kidung keagamaan, berdasarkan data yang didapat, materi yang diberikan oleh penyelenggara masih kurang dan perlu ditambahkan, sehingga Peserta memiliki pengetahuan dan keterampilan yang lebih.

\section{Pengaruh Utswa Dharma Gita terhadap peserta}

a) Peningkatan Sradha dan Bhakti dalam diri peserta;

Peserta Propinsi Yogyakarta berjumlah 54 orang yang terdiri dari tingkatan anak-anak, remaja dan dewasa. Dari ketiga katagori tersebut, data membuktikan hasil dari wawancara bahwa semua Peserta lomba mengatakan peningkatan terhdap ajaran agama, penghayatan terhadap isi kitab suci dan praktek keagamanan menjadi meningkat dan mendalam. Hal tersebut sudah sesuai dengan apa yang menjadi tujuan diadakannya Utsawa Dharma Gita.

Pemahaman terhadap agama terjadi karena Peserta secara rutin mempelajari dan mengucapkan isi kitab suci Veda, sebagai contoh pembacaan sloka, palawakya dan kekawin materi yang dibawakan berasal dari kitab suci. Semakin sering Peserta mengucapkan atau melafalkan sloka, maka Peserta tersebut akan menjadi lebih paham ajaran dan wejanganwejangan suci ajaran agama/kitab Veda. Seperti sloka di bawah ini:

Adhyesyate ca ya imam dharmyam samvadam avayoh,

Jnyanayadnyena tena'ham istah iti me matih. (Bhagawad Gita XVII.70)

Artinya: Dia yang selalu membaca percakapan suci (Bhagawad Gita), Aku anggap dia menyembahku dalam wujud Yadnya (yadnya dengan ilmu pengetahuan).

Jika diuraikan, orang yang selalu membaca dan melapalkan sloka kitab suci serta meresapi arti yang terkandung didalamnya sama dengan sembahyang memuja Hyang Widhi Wasa. Setiap hari membaca kitab suci merupakan Jnana Yadnya. Apa yang dinyatakan di kitab suci adalah sabda Hyang Widhi yang harus dipercaya dan dilaksanakan (Dharmagupta, 2013).

Pembacaan dan pelafalan mantram kitab suci merupakan cara pembelaajaran melalui Dharma Gita, Dharma Gita secara ber kesinambungan akan membentuk pribadi-pribadi yang sabar, jujur, damai, cinta kasih, rendah hati dan sebagainya. Dengan demikian bacalah kitab suci dengan rajin dan teratur, maka kedamaian akan tercapai dengan baik dan sempurna. Dengan melaksanakan Dharma Gita sesungguhnya kita sudah melaksanakan ajaran agama melalui mediasi nyanyian suci keagamaan (Cahyono, 2009). Salah satu bentuk Dharma Gita yang sarat dengan kebenaran universal sebagai berikut:

Kunang krama sang hyang Aditya, an wijil, humilangken petengning rat, mangkana tikang wwang mulahakening dharma, an hilangaken salwiring papa (Sarasamuscaya. 16 ).

Artinya: Seperti perilaku matahari yang terbit melenyapkan gelapnya dunia, demikianlah orang yang melakukan dharma, adalah memusnahkan segala macam perbuatan dosa. 
Tidak sedikit Peserta Yogykarta menyampaikan setelah sering membaca dan melafalkan sloka/mantram kitab suci, rasa bhakti meningkat, keadaan hati berubah, rasa nyaman dan damai begitu terasa. Selain itu, pernyataan Peserta yang merasakan begitu dituntun dan terasa diarahkan, menjadi inspirasi bagi generasi penerusnya.

Titib, 2014. Demikian pula dalam peningkatan penghayatan terhadap keagungan kitab suci, dengan tumbuhnya rasa bhakti dalam diri, maka semakin dalam penghayatan keagungan Tuhan melalui ajaran agama yang diturunkan-Nya, sehingga seorang dapat melakukan segala pekerjaan dan tugas kewajiban dengan sepenuh hati serta memusatkan pikiran senantiasa kepada-Nya seorang akan memperoleh karunia. Seperti wejangan Sri Krisna dalam Bhagawad Gita:

Ananyas cintayanto mam, ye janah paryupasate, tesam nityam abhiyuktanam, yogaksma wahamy aham.Bhagawad Gita IX.22

Artinya:Mereka yang memuja Aku sendiri, merenungkan Aku selalu, kepada mereka Aku bawakan apa yang mereka perlukan dan Aku lindungi apa yang mereka miliki.

Sloka di atas menegaskan bahwa Tuhan/Hyang Widhi memberikan jaminan kepada umat-Nya yang senantiasa bhakti kepada-Nya. Untuk mementapkan rasa bhakti, menghayati keagungan-Nya perlu senantiasa ditimbulkan. Itu yang terjadi pula kepada Peserta Utsawa Dharma Gita Peserta Yogyakarta, setelah melalui beberapa tahapan latihan dan pengulangan berkali-kali, rasa tenang dan damai muncul sehingga mereka sudah tidak lagi ada rasa takut dan was-was. Seperti Sloka Bhagawad Gita di bawah ini:

Yat karosi yad asnasi yaj juhosi dadasi yat, tat tapasyasi kauteya, tat kuruswa madarpanam.

Bhagawad Gita IX.27

Artinya: Apapun yang engkau kerjakan, engkau makan, engkau persembahan, engkau dermakan dan disiplin diri apapun engkau laksanakan, lakukan oh Arjuna hanya sebagai bhakti kepada Aku.

Wejangan Sri Krisna, sebagai punarwatara di dalam Bhagawad Gita di atas ditekankan kembali berulang-ulang oleh Yogi besar dalam abad modern ini, seratus tahun lalu yakni Swami Vivekananda: you hand on work but you heart on god dan ajaran ini senantiasa memberi semnagat kepada mereka yang menikmati manisnya kehidupan rohani melalui pengamalan agama.

Walaupun sibuk, terus berlatih sehingga harus pintar-pintar mengatur waktu dengan jam sekolah para Peserta, dengan bhakti dan rasa cintanya kepada Tuhan, peserta dimantapkan pula dalam menyelesaikan tugas yang dibebankan. Sehingga peserta merasa tidak capek dengan semua persiapan yang dilalui. Peningkatan Sradda dan Bhakti kepada Tuhan yang diimbangi dengan pengetahuan agama yang dalam membuat orang dengan mudah memahami segala apa yang terjadi dan dilewati dalam kehidupan ini.hasil ini menjadi sejalan dengan tujauan pemerintah dalam melaksanakan kegiatan Utsawa Dharma Gita yaitu meningkatkan sradda dan bhakti umat.

b) Memberikan nilai pendidikan;

Berdasarkan hasil pengamatan dan wawancara, beberapa hal penting yang ditemukan dalam penelitian adalah nilai religi, nilai budaya dan nilai sosial.

c) Nilai Pendidikan Religi;

Religi merupakan suatu kesadaran yang menggejala secara mendalam dalam lubuk hati manusia sebagai human nature. Religi tidak hanya menyangkut segi kehidupan secara lahiriah melainkan juga menyangkut keseluruhan diri pribadi manusia secara total dalam integrasinya hubungan ke dalam keesaan Tuhan (Rosyadi, 1995: 90). Nilai-nilai 
religious bertujuan untuk mendidik agar manusia lebih baik menurut tuntunan agama dan selalu ingat kepada Tuhan. Nilai-nilai religius yang terkandung dalam karya sastra dimaksudkan agar penikmat karya tersebut mendapatkan renungan-renungan batin dalam kehidupan yang bersumber pada nilai-nilai agama. Nilai-nilai religius dalam sastra bersifat individual dan personal. Kehadiran unsur religi dalam sastra adalah sebuah keberadaan sastra itu sendiri (Nurgiyantoro, 2005: 326).

Peserta Utsawa Dharma Gita memperoleh pendidikan agama secara otomatis, setiap lomba dan materi yang didapat tentunya tidak lepas dari unsur agama. peserta menyampaikan dalam mengikuti perlombaan Utsawa Dharma Gita banyak pendidikan agama yang didapat. Ajaran-ajaran agama terdapat dalam materi/naskah lomba. Dari naskah dan latihan tersebut peserta menambah pendidikan agama. dengan pendidikan agama yang kuat, maka tingkat religi seorang akan stabil dan meningkat. Pernyataan seperti itu pula yang disampaikan oleh peserta lomba. Terutama lomba dharma wacana, lomba pembacaan sloka dan pembacaan palawakya.

d) Nilai Pendidikan Budaya;

Nilai budaya merupakan tingkat yang paling abstrak dari adat, hidup dan berakar dalam alam pikiran masyarakat, dan sukar diganti dengan nilai budaya lain dalam waktu singkat. Uzey (2009: 1) berpendapat mengenai pemahaman tentang nilai budaya dalam kehidupan manusia diperoleh karena manusia memaknai ruang dan waktu. Makna itu akan bersifat intersubyektif karena ditumbuh-kembangkan secara individual, namun dihayati secara bersama, diterima, dan disetujui oleh masyarakat hingga menjadi latar budaya yang terpadu bagi fenomena yang digambarkan.

Peserta Utsawa Dharma Gita menjadi wahana untuk generasi penerus dalam melestarikan dan mengembangkan kebudayaan yang dimilikinya. Berbagai jenis lomba yang dilombakan, semua jenis lomba mengandung unsur kebudayaan di dalamnya, berdasarkan hasil wawancara, banyak peserta yang menyatakan senang karena dapat melestarikan kebudayaan melalui mengikuti perlombaan di Utsawa Dharma Gita. Dari serring latihan, sampai selesai mengikuti lomba, terjadi perubahan yang sangat tinggi, diawal peserta yang mengaku tidak suka dengan jenis lomba yang diikuti, dengan latihan dan ketekunan, peserta menjadi memahami dan menyukai lomba yang dibawakannya. Sehingga ini juga merupakan kesesuaian dengan tujuan diadakannya Utsawa Dharma Gita, yaitu melestarikan dan mengembangkan kebudayaan.

e) Nilai Pendidikan Sosial;

Nilai sosial mengacu pada hubungan individu dengan individu yang lain dalam sebuah masyarakat. Bagaimana seseorang harus bersikap, bagaimana cara mereka menyelesaikan masalah, dan menghadapi situasi tertentu juga termasuk dalam nilai sosial. Dalam masyarakat Indonesia yang sangat beraneka ragam coraknya, pengendalian diri adalah sesuatu yang sangat penting untuk menjaga keseimbangan masyarakat. Sejalan dengan tersebut nilai sosial dapat diartikan sebagai landasan bagi masyarakat untuk merumuskan apa yang benar dan penting, memiliki ciri-ciri tersendiri, dan berperan penting untuk mendorong dan mengarahkan individu agar berbuat sesuai norma yang berlaku. Uzey (2009: 7) juga berpendapat bahwa nilai sosial mengacu pada pertimbangan terhadap suatu tindakan benda, cara untuk mengambil keputusan apakah sesuatu yang bernilai itu memiliki kebenaran, keindahan, dan nilai ketuhanan.

Peserta lomba Utsawa Dharma Gita yang terdiri dari berbagai tingkatan umur, mulai dari anak-anak, remaja hingga dewasa. Dalam proses untuk mencapai perlombaan tentunya akan banyak interaksi sosial yang terjadi, mulai dari latihan, pertemuan-pertemuan hingga keberangkatan ke lokasi lomba. Peserta mengaku, banyak yang berubah didalam diri mereka, 
dari mengikuti lomba utsawa dharma gita banyak gejolak perasaan yang terjadi, muali dari menyesuaikan diri dengan pasangan lomba hingga menjaga solidaritas dengan seluruh kontingen. Nilai sosial yang didapat sangat beragam, mulia dari memahami dan mengenal pasangan lomba sampai saling berkerjasama. Banyak hal yang didapat oleh peserta lomba, lomba yang dilaksanakan di luar daerah menuntut kemendirian peserta dan saling menjaga, mengingatkan diantara peserta. Salah satu peserta meyampaikan sangat senang bisa ikut lomba, karena dapat menambah teman dan pengalaman dan berharap bisa selalu ikut disetiap penyelenggaraan kegiatan Utsawa Dharma Gita.

\section{KESIMPULAN}

Penyelenggaraan kegiatan Utsawa Dharma Gita menjadi suatu tugas dan tanggung jawab dari pemerintah keagamaan Hindu yang ada disetia daerah. Minimnya sumber daya manusia, membuat lembaga mengalami kesusahan dalam melengkapi formasi peserta lomba yang dilombakan. Dengan adanya kerja sama dengan para guru agama Hindu dengan lembaga agar setiap kegiatan Utsawa Dharma Gita tidak mengalami kesulitan. Dalam proses persiapan, diperlukan pendampingan penuh terhadap peserta lomba, sehingga setiap apa yang menjadi keperluan peserta lomba dapat segera diselesaikan. Kesiapan mental dan fisik merupakan modal yang paling utama dalam mengikuti kegiatan Utsawa Dharma Gita.

Dari hasil wawancara yang didapat, banyak manfaat yang positif yang didapat oleh peserta lomba. Dengan manfaat yang didapatkan menjadikan peserta lebih maju dan berpengalaman dallam bidang keagamaan Hindu. Peserta mendapat nilai-nila pendidikan yang memuat peserta mampu membentengi dan berinteraksi dengan orang lain. Nila religi yang didapat dapat dijadikan pondasi utama utuk meningkatkan sradda dan bhakti kepada Tuhan. Nilai kebudayaan yang didapat dapat digunakan sebagai ajang tugas generasi muda untuk menjaga dan melestarikan kebudayaan yang dimiliki. Sedangkan Nilai sosial menjadikan peserta mandiri dalam kehidupan sosial.

\section{KEPUSTAKAAN}

Kadjeng, I Nyoman, dkk. 1994. Sarasamuscaya, Dengan Teks Bahasa Sansekerta dan Jawa Kuna. Surabaya : Paramita.

Mantra, I.B. 1998. Bhagawad Gita, Surabaya:Paramita

Nurgiyantoro, Burhan. 2005. Teori Pengkajian Fiksi. Yogyakarta: Gajah Mada University Press.

Pudja, Gde. 1998. Bhagawad Gita. Surabaya. Paramita

Sugiyono. 2005. Memahami Penelitian Kualitatif. Bandung : Alfa Beta

Sukadiyanto. 2005. Penghantar Teori dan Metodelogi Melatih Fisik. Yogyakarta: PKO-FIKUNY. p. 40-68.

Sura, I Gede. 2001. Pengendalian Diri: Surabaya Paramita.

Titib, I Made. 2003, Tri Sandya, Sembahyang dan Berdoa, Surabaya: Penerbit Paramita

Uzey. 2009. "Macam-macam Nilai". Dalam http://uzey.blogspot.com/2009/09/ pengertian-nilai.

https://bimashindu.kemenag.go.id/media-berita.php?hal=detailberita\&id=380

https://pandejuliana.wordpress.com/2012/06/14/sejarah-utsawa-dharma-gita-udg/

http://dharmagupta.blogspot.co.id/2013/

http://baimlc09bi.blogspot.co.id/2013/06/penelitian-sastra-nilai-pendidikan.html https://griyawardani.wordpress.com/2011/05/19/nilai-nilai-pendidikan/ 